
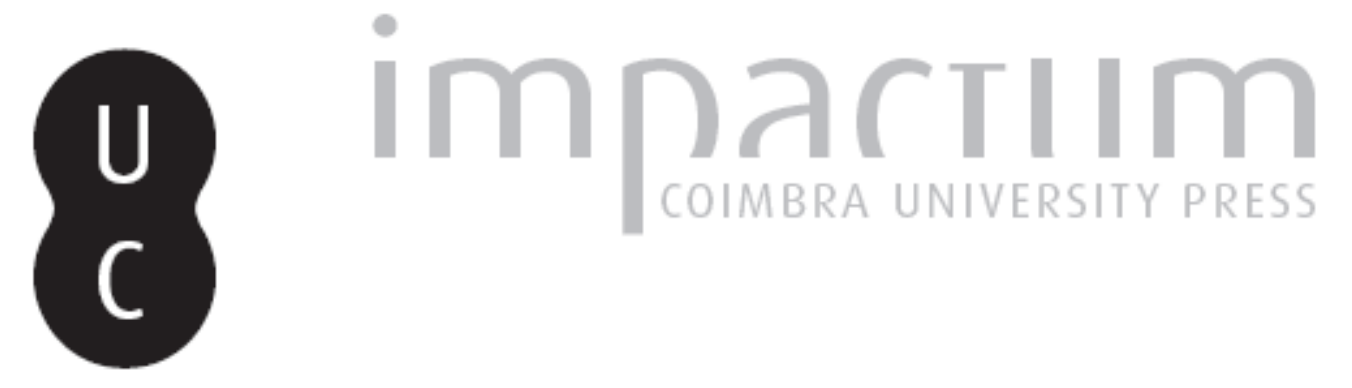

\title{
Nota sobre Garibaldi e as camisas ideológicas
}

\section{Autor(es): Loures, Carlos}

Publicado por: Imprensa da Universidade de Coimbra

URL persistente:

URI:http://hdl.handle.net/10316.2/42550

DOI:

DOl:https://doi.org/10.14195/0870-8584_6_8

Accessed : $\quad$ 26-Apr-2023 15:12:11

A navegação consulta e descarregamento dos títulos inseridos nas Bibliotecas Digitais UC Digitalis, UC Pombalina e UC Impactum, pressupõem a aceitação plena e sem reservas dos Termos e Condições de Uso destas Bibliotecas Digitais, disponíveis em https://digitalis.uc.pt/pt-pt/termos.

Conforme exposto nos referidos Termos e Condições de Uso, o descarregamento de títulos de acesso restrito requer uma licença válida de autorização devendo o utilizador aceder ao(s) documento(s) a partir de um endereço de IP da instituição detentora da supramencionada licença.

Ao utilizador é apenas permitido o descarregamento para uso pessoal, pelo que o emprego do(s) título(s) descarregado(s) para outro fim, designadamente comercial, carece de autorização do respetivo autor ou editor da obra.

Na medida em que todas as obras da UC Digitalis se encontram protegidas pelo Código do Direito de Autor e Direitos Conexos e demais legislação aplicável, toda a cópia, parcial ou total, deste documento, nos casos em que é legalmente admitida, deverá conter ou fazer-se acompanhar por este aviso.

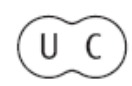




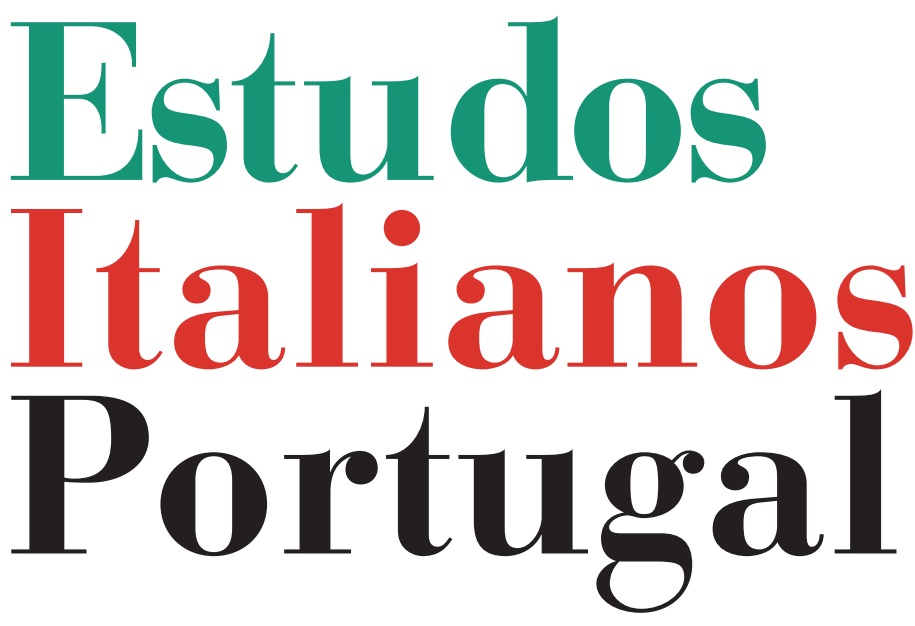

Instituto

Italiano

de Cultura

de Lisboa

Nova Série

$\mathrm{N}^{\circ} 6$ 


\title{
NOTA SOBRE GARIBALDI E AS CAMISAS IDEOLÓGICAS
}

\author{
Carlos Loures*
}

Giuseppe Garibaldi, um homem que teve um papel decisivo na unificação da Península itálica, foi considerado, tal como Giuseppe Mazzini e o Conde de Cavour, Pai da pátria italiana. Porém, uma outra designação lhe é atribuída, a de Herói dos dois mundos, pois além da sua intervenção em Itália foi um mítico combatente na América do Sul. Na chamada Guerra Grande do Uruguai, em 1842, foi nomeado capitão da armada uruguaia que se batia contra as forças do governador de Buenos Aires, Juan Manuel de Rosas.

Em 1843, durante a defesa de Montevideu, criou a Legiāo Italiana que se distinguia pelas suas berrantes camisas vermelhas. A Legião teve um papel decisivo, impedindo a tomada de Montevideu pelas tropas do presidente uruguaio Manuel Uribe. Garibaldi combatera já no Brasil ao lado dos farroupilhas na Guerra dos Farrapos. Em 1846, obteve rotundas vitórias nas batalhas de Cerro e de San Antonio. Tudo isto é sabido, mas podemo-nos perguntar porque usavam os seus voluntários camisas vermelhas.

* Poeta, romancista e ensaísta, foi editor das Publicações Alfa. De entre as suas obras poéticas, contam-se Arcano solar (1962), A voz e o sangue (1967, que lhe valeu seis meses de prisão), A poesia deve ser feita por todos (1970), O cárcere e o prado luminoso (1990, com prefácio de Manuel Simōes). Em prosa, publicou Talvez um grito (1985, Prémio Diário de Notícias), Mão incendiada (1995), A sinfonia da morte (2008), e tem no prelo um quarto romance, OXadrez sem Mestre. 
Foi a Raúl Leal, o poeta do Orpheu ${ }^{1}$, que ouvi pela primeira vez a versão de que as camisas vermelhas de Garibaldi tinham nascido de uma casualidade. Falávamos dos ícones simbólicos do fascismo - a saudação romana, as camisas, a idolatração da juventude. Estavam também o António José Forte, o Virgílio Martinho e mais alguns dos frequentadores habituais. O poeta José Carlos Gonzalez, que cantava bem, em voz baixa trauteou a Giovinezza e depois cantou o Cara al sol. O Lá vamos, cantando e rindo, não foi necessário, todos o conhecíamos. Isto terá sido num domingo de 1960. Um de nós falou no Futurismo de Marinetti como movimento genético do fascismo. Raúl Leal estaria com os seus 74 anos, muito lúcido e com uma prodigiosa memória, mas também muito surdo. Alheado da conversa, foi quando ouviu a palavra Futurismo que deu atenção. E tendo um de nós dito que lera e relera o Manifesto sem encontrar referências aos rituais litúrgicos adoptados por Mussolini, Leal, não sabendo explicar por que terá sido o negro escolhido pelos fascistas, falou no carácter casual das camisas vermelhas. Garibaldi comprara-as por atacado a um comerciante de Montevideu que as destinava a um matadouro de Buenos Aires. Eram vermelhas para não se notarem as manchas de sangue das rezes.

Nunca tínhamos ouvido aquela explicação. Muitos anos depois, num verbete de uma das enciclopédias que coordenei, vi a mesma explicação, mas com mais pormenores. Garibaldi ter-se-ia cruzado com o comerciante de roupas a meio do La Plata, e, vendo o lote de camisas, comprou-o, pagando mais do que o matadouro de Buenos Aires. Numa biografia de Garibaldi, escrita por Andrea Viotti, encontrei uma versão

${ }^{1}$ Raúl Leal (1886-1964) foi um dos elementos do movimento futurista em Portugal, ao lado de Guilherme Santa-Rita, Mário de Sá-Carneiro e Fernando Pessoa. Correspondeu-se, em 1917, com Filippo Tommaso Marinetti, comungando de muitas das suas ideias e divergindo relativamente a outras, como prova a correspondência entre ambos encontrada nos papéis de Fernando Pessoa 
um pouco diferente. Mas, sendo a única minimamente sustentada de que disponho, transcrevo-a:

Anzani chegou a Montevideu no mês de Julho de 1843. Pôs imediatamente em marcha as suas excelentes capacidades organizativas, transformando a Legião através do sistema de despedir os oficiais incompetentes. Deu-lhe também um uniforme e uma bandeira próprios. Compreendeu que, embora os uniformes não façam, em princípio, bons soldados, eles são, no entanto, necessários. Mas a legião carecia de fundos. Este seria sempre, com efeito, um problema para os garibaldinos. Nunca houve um exército tão esfarrapado, coçado e desalinhado! Por sorte, uma empresa de Montevideu que fabricava camisas vermelhas para os talhantes de Buenos Aires viu-se forçada, devido à guerra, a vender todo o seu stock. Eram túnicas folgadas, nada elegantes, que chegavam quase aos joelhos. Mas era melhor do que nada e, com um pouco de imaginação, até podiam ser consideradas um uniforme. Esta foi, portanto, a origem das famosas camisas vermelhas - origem mais prosaica e que nada teve a ver com as conotações psicológicas e políticas que mais tarde viriam a assumir. A nova bandeira mostrava o monte Vesúvio em erupção, sobre um fundo negro².

\section{Anzani é Francesco Anzani ${ }^{3}$, e nesta versão de Andrea Viotti} terá sido ele e não Garibaldi quem negociou com a empresa

${ }^{2}$ Andrea Viotti, Garibaldi. The Revolutionary and His Men, Dorset, Blandford, 1979, trad. do autor.

3 "Nato ad Alzate (Como) l'11 novembre 1809, rimase presto orfano, e per cura dello zio Giuseppe, parroco del paese, fu posto prima nel seminario di Castello, sopra Lecco, poi, nel '26, nel collegio di Gorla, donde passò (biennio 1829-30) al liceo di Como. [...] A questi anni (nel '28 risulta assente dal collegio di Gorla per malattia) dovrebbe collocarsi la partecipazione dell'Anzani alla lotta greca per l'indipendenza, in cui sarebbe stato ferito: ne accenna genericamente in una lettera al fratello Giuseppe (da Montevideo, 17 giugno 1847). Iscrittosi alla fine del ' 30 al corso di matematica dell'università di Pavia, non terminò il biennio. Lo si ritrova esule in Francia, dove sembra partecipasse al moto insurrezionale di Parigi del 5-6 giugno '32. Si trasferì poi nel Portogallo, e si arruolò sotto il nome di Ferrari tra i Volontari di Oporto, contro don Miguel, meritandosi una medagli [...] Nel 1838 l'Anzani rimpatriò per una missione politica, ma, sbarcato a Genova, fu arrestato dalla polizia sarda [...] fu poi costretto a libertà vigilata in Alzate. Chiesto il passaporto per l'America, partì il 21 aprile 
uruguaia a compra das túnicas vermelhas que desencadeariam, no século seguinte, a moda de tão trágicas conotações.

Para melhor compreendermos a aceitação das camisas vermelhas como uniforme, é preciso ter em conta a tipologia geral dos uniformes e equipamentos militares da época. As fardas berrantes existiam por vários exércitos europeus. Só em 1870 houve um primeiro alarme - os franceses marcharam para a guerra com a Prússia com dolmanes azuis e calças vermelhas. Há quem associe a derrota fulminante que os prussianos lhes infligiram ao facto de serem alvos perfeitos para as suas modernas espingardas de repetição. A Guerra Civil Americana (1861-1865) fora um primeiro sinal de que guerra e folclore são coisas diferentes. Os uniformes do Sul, de um azul claro acinzentado e discreto, anunciavam já os cuidados que iriam existir no futuro próximo. Os do Norte, azuis escuros, já estavam mais desadequados. A viragem ter-se-á dado devido à evolução do armamento, nomeadamente das espingardas. Precisamente durante a Guerra Civil Americana, verificou-se um grande incremento na indústria de guerra, com o aparecimento de espingardas e carabinas de repetição, com recarregamento mecânico, cartuchos impermeáveis, metálicos. A que viria a seguir, Winchester 44, por exemplo, seria quase uma lenda. As armas de percussão davam lugar a outras que disparavam doze tiros por minuto, com um alcance muito superior e com dispositivos ópticos

1839, e sbarcò in Brasile a Rio Grande do Sul. S’impiegò in una impresa commerciale, a San Gabriele; ma presto schieratosi coi Farappas contro l'imperatore del Brasile, si batté eroicamente al comando della fanteria di Juan Antonio. A San Gabriele si legò d'amicizia con Garibaldi; quando questi partì per la repubblica di Montevideo, lasciò il comando dell'esercito all'Anzani, che lo tenne fino all'accomodamento della questione riograndese. Si riunì poi a Garibaldi, che si era schierato in difesa della libertà uruguaiana, e che durante l'assedio di Montevideo aveva costituito una Legione Italiana, affidandone il comando all'Anzani, che accettò nel luglio 1843", Dizionario Biografico degli Italiani, direttore Raffaele Romanelli, www.treccani.it/biografie (2010). 
que permitiam pontarias certeiras. Túnicas vermelhas teriam sido, no último quarto do século XIX, uniformes suicidas.

Seria interessante empreender aquilo que não cabe nas dimensóes deste pequeno trabalho, uma hermenêutica da simbologia fascista, para resposta à pergunta que alguém naquele Domingo fez na mesa do Gelo, muito perto da mesa do Buiça, o porquê das camisas ideológicas do século $\mathrm{XX}^{4}$. Os fascistas apoderaram-se da simbologia garibaldina que, na sua origem, tinha mais a ver com os ideais dos communards do que com o lirismo operático dos camicie nere. O fascínio dos fascistas pela morte, como ficou patente durante a lição magistral de Unamuno, foi sugerido por alguém, na tal conversa no $G e l 0^{5}$, para justificar a escolha do negro para as suas camisas ${ }^{6}$. $\mathrm{Na}$ Guerra Civil de Espanha, nas Brigadas Internacionais, houve um Batalhão Garibaldi. Do lado dos falangistas existiu também uma formação denominada garibaldina. Lembro que seria a 52. ${ }^{a}$ Brigada Garibaldina da resistência italiana que, em 27 de Abril de 1945, prenderia Benito Mussolini. Seguiu-se a sua execução sumária e o fuzilamento ao lado de Clara Petacci. Garibaldi e as camisas vermelhas são, pois, mitos tutelares da História de Itália.

Hoje, as camisas ideológicas ostentam cores discretas e etiquetas como Armani, Dolce \& Gabanna, Colcci, Gucci, Lino Villaventura, Valentino... Nelas, o sangue das reses também passa despercebido.

${ }^{4}$ Os primeiros a inspirarem-se nas camisas vermelhas dos garibaldinos foram os camisas negras do partido organizado por Benito Mussolini. Outros se seguiram: na Alemanha nazi, as camisas pretas foram destinadas às SS (Schutzstaffel), a guarda pessoal de Hitler. As SA (Sturmabteilung) usavam camisas castanhas. Os fascistas da União Britânica de Fascistas, de Oswald Mosley, optaram também pelo negro. Nos Estados Unidos, o führer local, William Dudley Pelley, escolheu as Shirts Silver (camisas prateadas) para a sua Legião de Prata da América. O azul foi a cor preferida por numerosos partidos e formações paramilitares de extrema direita: a Falange Española, de José Antonio Primo de Rivera, os Blueshirts irlandeses, de Eoin O’Duffy, para o seu Army Comrades Association, os Blueshirts da organização canadiana Canadian 
National Socialist Unity Party, os franceses do Solidarité Française e do Parti Franciste, bem como os chineses da Sociedade das Camisas Azuis. No México, os fascistas locais usaram camisas douradas. O Movimento Integralista Brasileiro, de Plínio Salgado, adoptou camisas verdes. Em Portugal, como sabemos, a cor das organizações patrióticas foi também o verde, usado pela Legiāo Portuguesa e pela Mocidade Portuguesa. Rolão Preto, no seu movimento nacional-sindicalista, seguiu Itália e as suas camisas negras.

${ }^{5}$ Em 12 de Outubro de 1936, durante uma sessão solene na sala de actos da Universidade de Salamanca, Miguel de Unamuno, seu reitor, pronunciou um vigoroso discurso contra as atrocidades que se estavam a cometer na guerra desencadeada em Julho pela sedição franquista. O general Millán Astray, que entretanto chegara à frente de um grupo de soldados, exigiu que a palavra lhe fosse concedida. Alguém gritou ;Viva la muerte!. Unamuno fez então uma intervenção brilhante em defesa dos valores éticos da Humanidade. Fora de si, Millán gritou, ¡Muera la inteligencia! Unamuno concluiu: "Éste es el templo de la inteligencia! ¡Y yo soy su supremo sacerdote! Vosotros estáis profanando su sagrado recinto. Yo siempre he sido, diga lo que diga el proverbio, un profeta en mi propio país. Venceréis, pero no convenceréis, porque convencer significa persuadir, y para persuadir necesitáis algo que os falta: razón y derecho en la lucha. Me parece inútil pediros que penséis en España”.

${ }^{6}$ Uma hipótese colocada por um amigo italiano a quem pus a questão é a de que a inspiração da cor negra tenha sido motivada pelo facto de o pai de Mussolini, que the deu o nome de Benito em homenagem ao estadista mexicano Benito Juarez, ter ideias anarquistas. Como se sabe, a cor negra é a cor adoptada pelo movimento anarquista, desde que Louise Michel, cerca de 1880 , propôs a bandeira negra como símbolo do movimento. 